\title{
Daily burdens of recipients and family caregivers after lung transplant
}

\author{
Jiayun XU, RN, BSN, Oluwatobi Adeboyejo, RN, BSN, Erin Wagley, MS, Jill Aubrecht, RN, \\ MSN, MBA, Mi-Kyung Song, RN, PhD, Lori Thiry, BA, and Annette DeVito Dabbs, RN, PhD \\ Johns Hopkins University School of Nursing, Baftlmore (JX), Howard University Hospital, \\ Washington, DC (OA), University of Pittsburgh, Pittsburgh, Pennsylvania (EW, JA, L T, ADD), \\ University of North Carolina, Chapel Hill (MKS)
}

\section{Abstract}

Context-Lung transplant recipients are prescribed a complex medical regimen that is thought to be-burdensome and to interfere with daily activities of recipients and family caregivers. Yet empirical studies describing the activities that lung transplant recipients and their family caregivers perform on a typical day and the emotions associated with performing these activities are lacking.

Objective-To identify the daily activities and burdens after lung transplant.

Design-The Day Reconstruction Method and content analysis were used to reconstruct a typical day for lung transplant recipients and their family caregivers.

Setting-The adult cardiothoracic transplant program of The University of Pittsburgh Medical Center.

Participants-Twenty-one dyads of lung transplant recipients and their family caregivers.

Main Outcome Measures-Variables of interest included lung transplant recipients' and family caregivers' daily activities and associated emotions, sociodemographics, clinical characteristics, and patient-reported outcomes of quality of life, symptoms of depression and anxiety, and functional performance.

Results-Participants reported 286 daily activities and 138 associated positive and negative emotions. No activities or emotions were uniquely reported by lung transplant recipients or caregivers, providing evidence of the shared responsibility for caregiving and health maintenance. Most activities reported by caregivers and lung transplant recipients were health-related. Compared with lung transplant recipients, caregivers reported positive emotions more often, yet reported lower overall daily mood. This finding is consistent with results of previous studies indicating that specific caregiving tasks were typically rewarding for caregivers, but overall, care giving takes its toll.

Conclusion-Findings enhance our understanding of the burdens lung transplant recipients and caregivers face and point to the need for further support for dyads after lung transplant.

\section{C2012 NATCO, The Organization for Transplant Professionals}

Correspondirig autho'r: Annette DeVito Dabbs, RN. PhD, FAAN. University of Pittsburgh, School of Nursing, 336 VB, 3500 Victoria Street, Pittsburgh, PA 15261 (ajdst42@ pitt.edu) To purchase electronic or print reprints, contact: The InnoVision Group 101Columbia, Aliso Viejo, CA 92656 Phone (800) 899-1712 (ext 532) or (949) 448-7370 (ext 532) Fax (949) 362-2049 reprints@aacn.org.

Financial Disclosures This study was funded by grant NROI0711 (DeVito Dabbs, principal investigator) from the National Institute of Nursing Research and a grant from the University of Pittsburgh School of Nursing, Undergraduate Research Fund. 
Since the 1980s, more than 30000 persons have undergone lung transplantation worldwide, with the goals of prolonging survival and improving health-related quality of life (HRQOL). ${ }^{1}$ To increase the likelihood of achieving these goals, lung transplant recipients (LTRs) are prescribed a complex medical regimen and expected to perform a variety of health-promoting behaviors. These routines are often burdensome and disruptive, and they inteliere with other activities and interests of patients and their family members. ${ }^{2,3}$ In order to understand the' magnitude and effects of illness burdens on the quality of LTRs' extended lives, it is important to measure daily activities and care-related burdens for LTRsand their families. However,-empirical studies describing the activities tllat LTRs and their family caregivers actually perfonn on a typical day and an understanding of the emotions and, burdens associated with perf.onning these activities are lacking.

\section{IIIness Burden and HRQOL}

LTRs are prescribed a complex multicompone:1t home regimen that includes adhering to multiple lifelong medications, performing self-monitoring (eg, home-based spirometry, symptoms, vital signs), communicating changes in their condition to the transplant team in a timely manner, returning for routine assessments (eg, laboratory tests, pulmonary function tests, bronchoscopies, and follow-up appointments), as well as following general healthy lifestyle habits (eg, diet and exercise), ${ }^{4,5}$ LTRs and their families also face chronic stressors such as the unpredictability of graft survival and susceptibility to infections, rejection, cancers, and other complications after transplant. Management of health after lung transplant is thought to be burdensome, intrude on LTRs' and their families' daily lives, and undermine the quality of their lives. Yet LTRs' ratings of HRQOL are typically high and comparable to ratings of other organ recipients during the first year after transplant and thus may belie such burdens. ${ }^{6}$

Based on an exhaustive review of studies that examined quality of life (QOL) after solid organ transplant (including in LTRs), Dew and colleagues ${ }^{7}$ concluded that (I) HRQOL across all domains (physical, mental health/cognitive status, and social functioning) and overall perception of HRQOL improve from before to after transplant, although HRQOL does not improve in every patient nor does it improve equally across all domains or across all organ types; (2) HRQOL after transplant does not equal that of healthy nonpatient samples; and (3) transplant recipients overwhelmingly rate their global QOL highly, despite only modest improvements in their various domain-specific ratings. Declines in HRQOL over time are generally due to the increase in comorbid conditions and symptom burden associated with complications of immunosuppression and the development of chronic rejection. ${ }^{8-11}$

\section{Caregiver Burden}

The chronic stress of caregiving negatively affects caregivers' health, the performance of self-care behaviors to promote their own health or manage their own health problems, and overall caregiver survival. ${ }^{12-15}$ Furthermore, caregiver overload, a caregiver's appraisal of the immediate impact of care-related stress on his or her time and energy, ${ }^{16,17}$ such as caring for others with complex medical regimens, mediates the relationship between caregiver stress and health. ${ }^{12,13,18,19}$ Because considerable individual variability exists in caregivers' appraisals of care-related activities, stress, and overload, ${ }^{12,13,18}$ caregivers' appraisals of burden arld the experience of care giving for specific populations must be directly assessed. The major areas of burden that families of transplant recipients (including LTRs) face are changes in family roles and responsibilities, time constraints, worry about recipients' health, and financial concems. ${ }^{2}$ 
Illness burden and, more recently, caregiver burden are recognized as important to HRQOL, and the literature is replete with numerous measures of these constructs. However, generic measures of illness and caregiver burden fail to capture the daily activities that LTRs and their caregivers perform. Furthermore, global measures of burden and HRQOL lend little to our understanding of the subjective emotions that LTRs and caregivers experience while peliorming daily activities and the difference in perceived burden between LTRs and caregivers. In addition, the majority of studies assessing HRQOL after cardiothoracic transplant were conducted with heart recipients. ${ }^{20}$ Based on the lack of measures specific to lung transplant and the concern that global measures of illness and caregiver burden may not accurately reflect the true impact of managing health after lung transplant, the purpose of this study was to assess the daily activities and burdens of LTRs and their family caregivers in order to increase clinicians' understanding of their experience and guide the development of supportive interventions.

\section{Methods}

\section{Design}

This study used the Day Reconstruction Method (DRM) ${ }^{21}$ and content analysis to assess daily burdens of LTRs and their family caregivers. The goal of the DRM is to accurately reconstruct the activities and experiences of a typical day, and thus it was used to quantify the burden of illness associated with the regimen after lung transplant. Each LTR and caregiver was interviewed at least once during the first 6 months after transplant to coincide with routine follow-up visits to the transplant center.

\section{Sample}

The sample included $21 \mathrm{~L}$ TRs who recently received a transplant at the University of Pittsburgh Medical Center's adult cardiothoracic transplant program who were participating in a parent study about self-care after transplant, were well enough to be interviewed, and whose primary family caregivers agreed to be intervievved. The sample represented $66 \%$ of eligible dyads that were approached consecutively during a 6-month period. The study was approved by the University of Pittsburgh's institutional review board, and all participants provided informed consent.

\section{Measures}

As part of the parent study, data were collected to describe characteristics of LTRs including patientreported outcomes (HRQOL, functional performance, psychological distress, and symptom burden) because of their relevance to the assessmenl of illness burden.

The Medical Outcome Study Short Form 36, version 2.0 (SF-36v2) 22,23 was used to assess LTRs' perceptions of their global HRQOL. Physical and mental component scales were calculated such that resulting values were $T$ scores normed against a mean of 50 and a standard deviation of 10 (higher scores being more positive with less limitation), ${ }^{22}$ Internal consistency for the physical and mental components were 0.83 and 0.83 , respectively, in our previous studies of LTRs. ${ }^{24}$

The Karnofsky Performance Status Scale was used to characterize the impact of disease and its burdens on functional performance as rated by data collectors using a 10-point rating scale that ranged from normal functioning (100) to moribund (10); higher scores reflected better performance. ${ }^{25,26}$ The Karnofsky is a reliable and valid measure of perfonnance. ${ }^{27,29}$

LTRs' perceived psychological distress was measured by using the anxiety and depression subscales of the Symptom Checklist 90-Revised (SCL-90-R). ${ }^{30}$ Items arerated on a 5-point 
scale $(\mathrm{O}=$ not at all to $4=$ extremely distressed $)$. Subscale scores were computed by averaging items. Higher scores reflect higher levels of distress. Internal consistency for the anxiety subscale was 0.88 and for the depression subscale was 0.80 in our previous studies. ${ }^{24}$

The Questionnaire for Lung Transplant Patients (QLTP), a lung transplant-specific, selfreport measure was used to assess the presence of up to 56 physical symptoms. Scores were computed by summing the symptoms endorsed as bothersome. The psychometric properties of the QLTP were reported previously and show high reliability and validity. ${ }^{31-33}$

\section{Interviews}

LTRs and their caregivers were interviewed face-to-face, and concurrently but in separate rooms, to promote frank conversation and eliminate the possibility of comparing their responses and recollection of the day's events. Interviews were conducted by interviewers who were trained to use the DRM format and audio recorded. ${ }^{21}$ This semistructured interview method combines a time-study approach with techniques for gathering information about the emotions associated with each activity. Participants were asked to recall the sequence of activities performed on a typical day (within the last 3 days) and to describe the emotions associated with each activity. Per the DRM, participants were also asked to describe their mood by determining the percentage of their day spent in a very good mood, mildly pleasant mood, a little low or initable mood, and a bad mood.

\section{Analysis Procedures}

Instruments were scored and presented by using means and standard deviations or proportions. The interviews were transcribed, reviewed, and coded using qualitative content analysis techniques ${ }^{34}$ by 2 researchers (JX and OA under the direction of ADD) to promote consistency and achieve consensus. The analysis generated a diverse list of activities and emotions representing the pooled responses of LTRs and their caregivers. Similar activities were then grouped and collapsed into broader categories. Emotions were labeled positive or negative.

\section{Results}

\section{Sample Characteristics}

Sociodemographic and clinical characteristics of the 21 dyads are shown in Table 1 and minored those of the population of LTRs worldwide. ${ }^{1}$ Also presented is a summary of recipients' HRQOL, functional performance, psychological distress, and symptom burden. The mean SF-36v2 mental health component score (49.67) was nearly normal (normed mean, 50), and LTRs rated their mental health better than their physical health (49.67 vs 38.7). These levels and the higher mental verstis physicai component scores are typical of other LTRs measured during the early posttransplant period, ${ }^{24}$ Average Karnofsky functional performance ratings (mean, 6733) for the sample meant that recipients were capable of living fairly independently at home but required occasional assistance with personal needs. ${ }^{2}$ LTRs reported more SCL-90 depressive symptoms (0.52) than symptoms of anxiety (0.34), yet both scores reflected low levels of psychological distress. LTRs endorsed, on average, approximately 20 of the possible 56 physical symptoms assessed by the QLTP, which was comparable to symptom reports of other LTRs measured during the early posttransplant period. ${ }^{33}$

\section{Daily Activities}

Participants reported a total of 286 different daily activities. No activities were uniquely reported by LTRs or caregivers. Related activities were grouped into 13 main categories (see Table 2 for the list of categories, number of activities per category, and sample activities). 
Nearly one-third of reported activities (30\%) were health-related and included medication taking, health monitoring, medical appointments, and therapy or exercise. Leisure accounted for only $20 \%$ of daily a6tivities. The balance of activities was related to routine household and caregiving activities.

\section{Emotions and Mood}

Participants reported a total of 138 different emotions associated with performance of their daily activities (Table 3). Similarly to activities, no emotions were reported only by LTRs or only by caregivers. Fifty-six percent of the emotions were considered to be positive, such as accepting, encouraging, hopeful, and relieved; the remaining $44 \%$ of emotions, such as feeling abused, overwhelmed, and pressured, were considered to be negative, The Figure is a graphical representation Df the percentage of the day that LTRs and caregivers spent in a very good, mildly pleasant, low/irritable, or bad mood, Compared with LTRs, caregivers reported less time spent per day in a very good mood ( $40 \%$ vs $60 \%)$, yet they reported positive emotions more frequently than LTRs during their interviews, Both LTRs and caregivers spent less than $10 \%$ of their day in a bad mood.

\section{Other Notable Findings}

During the interviews, participants often expressed more in-depth feelings and perspectives than the list of activities and emotions alone would indicate, For example, a 61-year-old male LTR expressed the following concerns at 6 months after lung transplant. He was following the posttransplant medical regimen, doing everything he was supposed to, but still felt depressed, had pain, and was expressing extreme frutration about not being able to live life to the fullest.

It's got to get better. Of all the people in the world, I should be living life to the fullest. Two of the reasons are this depression and this pain, and there has to be something we haven't figured out yet because I'm taking medications for everything else and I still feel this way, It's very depressing to tell about my day because every day is the same.

Another example was expressed by an adult son caring for his mother:

It's just that I was using my sixth vacation day of the year, ..., well it's uhh you know ... I'm not gonna have any time for me but you know, it's important for her. It was either go to work yesterday or [take her to her clinic appointment] ... so, you know ... it's a burden, but it's more important at this point for me to make her healthy than it is to take a vacation. Although it's affecting me, I understand it....

This caregiver's sentiments about the impact of the sacrifices and tradeoffs (like using his vacation time to support his mother) was a common theme throughout his interview, Quotes such as these added richness to our understanding of the unique experiences of LTRs and their caregivers and thus were included to provide more insight into burden of care than reflected by the lists of activities and emotions.

\section{Discussion}

The similarity between these recipients' sociodemographic and clinical characteristics and patientreported outcome measures with other LTR cohorts make these results generalizable to other recipients soon after lung transplant. Although the sample comprised a large proportion of white participants, with relatively high educational and income levels, participants were not selected on the basis of any sociodemographic characteristics. OUT findings -demonstrate the types of activities that LTRs and family caregivers routinely performed on a typical day and highlight the high proportion of daily activities that were 
health related (30\%) and the relatively low proportion of activities that reflected rest and leisure $(20 \%)$. The high proportion of health-related daily activities highlights the complexity of the medical regimen after lung transplant. As no activities were uniquely reported by LTRs or caregivers, these findings provide evidence of the shared responsibility for care giving and health maintenance after lung transplant.

To our knowledge, this is the first study to identify the emotions that LTRs and caregivers reported during the performance of their daily activities and the first to describe ratings of their mood during a typical day. L TRs and family caregivers reported a mixture of both positive and negative emotions. Interestingly, LTRs reported spending a greater portion of their day in a better mood than caregivers, yet caregivers associated positive emotions with the performance of activities more often than LTRs. The tendency for LTRs to rate their mood highly is consistent with the elation that most LTRs typically experience during their first few months at home after lung transplant. ${ }^{35}$ The lower levels of psychological distress and higher mental component scores reported by LTRs are consistent with their reports of overall good mood.

The fact that caregivers replied positive emotions more often, yet reported lower overall daily mood, is consistent with results of previous studies indicating that specific caregiving tasks were typically rewarding for caregivers, but on the whole, care giving in combination with other roles and responsibilities such as household and job-related tasks, takes its toll. ${ }^{12}$ Lower overall caregiver daily mood may also be attributed to the management of complex multicomparrent home regimens and changing family dynamics. $2,4,5$

\section{Human Subject Protection}

The ethical integtity of the study was achieved in several ways. All participants provided written informed consent. All data were stored in locked -cabinets or password-protected files available to study staff only to maintain confidentiality. Data were deidentified for analysis and results reported in aggregate to maintain privacy. Patients and family caregivers were interviewed separately in private areas to promote honest and open sharing of experiences without fear of hurting the other dyad member.

\section{Limitations}

The richness of descriptions of daily burdens and experiences may have been reduced during analysis because the content of interviews was presented as activities and emotions. The interviews were limited to 30 minutes to avoid fatigue and to reduce the participants' time commitment, which may have truncated their contributions. The patient-reported outcomes of LTRs were analyzed in aggregate, rather than at the individual recipient level, thus preventing researchers from determining conelates between patient-reported outcomes, activities, and emotions. Caregivers were not participants in the parent study; therefore, data for patient-reported outcomes such as HRQOL, symptoms, and psychological distress were not available for comparison.

\section{Implications}

These findings may assist nurses to understand better the daily activities and burdens shared by LTRs and their caregivers and can be llsed to inform the development of interventions such as providing additional support at home to reduce burden and the negative influences of that burden on caregiver mood. Caregivers are an integral part of the recovery and the health maintenance ${ }^{36}$ of recipients, which points to the need to attend to caregivers' concerns during LTR clinic visits. Furthermore, open lines of communication and support 
between transplant clinicians and family caregivers are likely to identify caregiver burden in a timely manner. ${ }^{37}$

Further exploration about the impact of burden on the health of caregivers is also warranted because caregivers' emotional and physical well-being has reciprocal effects on the course of recipients' health over time. ${ }^{2,37}$ Future research in this area may be aimed at exploring coping styles, social support, and the quality of the dyadic relationship, because LTRs and caregivers share responsibilities and the strength of the dyadic relationship is a critical factor in predicting distress and burden for caregivers and recipients in transplant and other illness populations? $2,12,38$

\section{Conclusion}

In conclusion, the high proportion of healthrelated daily activities performed by both patients and caregivers after lung transplant highlights the complex medical regimen and health challenges that LTRs and caregivers face. Furthermore, lung recipients and family caregivers appear to share many responsibilities, yet the toll these burdens take on family caregivers reinforces the need to attend to their needs as well as the needs of patients to improve the QOL for the dyads.

\section{Acknowledgments}

The authors extend our appreciation to the recipients and caregivers who graciously devoted time to participate in this study.

\section{References}

1. Christie JD, Edwards LB, Aurora P, et al. The Registry of the International Sociely for Heart and Lung Transplantation: Twenty-sixth official adult lung and heart-lung transplantation report-2009. J Heart Lung Transplant. 2009; 28(10):1031-1049. [PubMed: 19782285]

2. Dew MA, Myaskovsky L, DiMartini AF, Switzer GE, Schulberg HC, Kormos RL. Onset, timing and risk for depression and anxiety in family caregivers to healt transplant recipients. Psychol Med. 2004; 34(6):1065-1082. [PubMed: 15554577]

3. Devins GM. Illness intrusiveness and the psycholsocial impact of lifestyle disruptions in chronic life-threatening disease. Adv Renal Replace Ther. 1994; 1(3):251-263.

4. DeVito Dabbs AJ, Hoffman LA, Iacono AT, Zullo TO, McCurry KR, Dauber JH. Are symptom reports useful for differentiating between acute rejection and pulmonary infection after lung transplantation? Heart Lung. 2004; 33(6):372-380. [PubMed: 15597291]

5. Teichman BJ, Burker EJ, Weiner M, Egan TM. Factors associated with adherence to treatment regimens after lung transplanlation. Prog Transplant. 2000; 10(2):113-121. [PubMed: 10933765]

6. Myaskovsky L, Dew MA, McNulty ML, et al. Trajectories of change in quality of life in 12 month survivors of lung or heart transplant. Am J Transplant. 2006; 6(8):1939-1947. [PubMed: 16889548]

7. Dew MA, Switzer GE, Goycoolea JM, et al. Does transplantation produce quality of life benefits? A quantitative analysis of the literature. Transplantation. 1997; 64(9):1261-1273. [PubMed: 9371666]

8. Gross CR, Savik K, Bolman RM, Hertz MI. Long term health status and quality of life outcomes of lung transplant recipients. Chest. 1995; 108(6):1587-1593. [PubMed: 7497766]

9. Kugler C, Geyer S, Gottlieb J, Simon A, Haverich A, Dracup K. Symptom experience after solid organ transplantation. J Psychosom Res. 2009; 66(2):101-110. [PubMed: 19154852]

10. Vermeulen KM, Ouwens JP, Van der Bij W, de Boer WJ, Koeter GH, TenVergert EM. Long-Term quality of life in patients surviving at least 55 months after lung transplantation. Gen Hosp Psychiatr. 2003; 25(2):95-102.

11. Vermeulen KM, Groen H, van der Bij W, Erasmus ME, Koeter GH, TenVergert EM. The effect of bronchiolitis obliterans syndrome on health related quality of life. Clin Transplant. 2004; 18(4): 377-383. [PubMed: 15233813] 
12. Schulz R, Beach SR. Caregiving as a risk factor for mortality: the Caregiver Health Effects Study. JAMA. 1999; 282(23):2215-2219. [PubMed: 10605972]

13. Son J, Emo A, Dennis G, et al. The Caregiver Stress Process and Health Outcomes. J Aging Health. 2007; 19(6):871-887. [PubMed: 18165286]

14. Vitaliano PP, Zhang J, Scanlan JM. Is caregiving hazardous to one's physical health? A metaanalysis. Psychol Bull. 2003; 129(6):946-972. [PubMed: 14599289]

15. Zhang J, Vitaliano PP, Lin HH. Relations of caregiving stress and health depend on the health indicators used and gender. Int J Behav Med. 2006; 13(2):173-181. [PubMed: 16712435]

16. Pearlin LI, Mullan JT, Semple SJ, Skaff MM. Caregiving and the stress process: an overview of concepts and their measures. Gerontologist. 1990; 30(5):583-594. [PubMed: 2276631]

17. Zarit, SH.; Davey, A.; Edwards, AB.; Femia, EE.; Jarrott, SE. Family caregiving: research findings and clinical implications. In: Edelstein, B., editor. Clinical Geropsychology. Elsevier; Oxford, England: 1996. p. 499-523.

18. Aneshensel, CS.; Pearlin, LL.; Mullan, JT.; Zarit, SH.; Whitlatch, CJ. Profiles in Caregiving: The Unexpected Career. Academic Press; San Diego, CA: 1995.

19. Shaw WS, Patterson TL, Semple SJ, et al. Longitudinal analysis of multiple indicators of health decline among spousal caregivers. Ann Behav Med. 1997; 19(2):101-109. [PubMed: 9603684]

20. Dew, MA.; Manzetti, JD.; Goycoolea, JR., et al. Psychosocial aspects of transplantation. In: Smith, SL.; Ohler, L., editors. Organ Transplantation: Concepts, Issues, Practice and Outcomes. MedicaLogic/Medscape; New York, NY: 2002.

21. Kahneman D, Krueger AB, Schkade DA, Schwarz N, Stone AA. A survey method for characterizing daily life experiences: The Day Reconstruction Method. Science. 2004; 306(5702): 1776-1780. [PubMed: 15576620]

22. Ware, JE.; Kosinski, M.; Keller, SD. SF-36 Physical and Mental Summary Scales: A User's Manual. The Health Institute; Boston, MA: 1994.

23. Ware JE, Sherbourne CD. THE MOS 36-item Short-Form Health Survey (SF-36): I. Conceptual Framework and Item Selection. Med Care. 1992; 30(6):473-483. [PubMed: 1593914]

24. DeVito Dabbs AJ, Dew MA, Myers B, et al. Evaluation of a hand-held, computer-based intervention to promote early self-care behaviors after lung transplant. Clin Transplant. 2009; 23(4):537-545. [PubMed: 19473201]

25. Karnofsky DA, Abelmann WH, Craver LF, Burchenal JH. The use of the nitrogen mustards in the palliative treatment of cancer. With particular reference to bronchogenic carcinoma. Cancer. 1948; 1(4):634-656.

26. Karnofsky, DA.; Burchenal, JH. The clinical evaluation of chemotherapeutic agents in cancer. In: MacLeod, CM., editor. Evaluation of Chemotherapeutic Agents. Columbia University Press; New York, NY: 1949. p. 191-205.

27. Buccheri G, Ferrigno D, Tamburini M. Kanrofsky and BCOG perfonnance status scoring in lung cancer; a prospective, longitudinal study of 536 patients from a single institution. Eur J Cancer. 1996; 32A(7):1135-1141. [PubMed: 8758243]

28. Mor V, Laliberte L, Morris JN, Wiemann M. The Karnofsky Performance Status Scale: an examination of its reliability and validity in a research setting. Cancer. 1984; 53(9):2002-2007. [PubMed: 6704925]

29. Schag CC, Heinrich RL, Ganz PA. Karnofsky Performance Status revisited: reliability, validity, and guidelines. J Clin Oncol. 1984; 2(3):187-193. [PubMed: 6699671]

30. Derogatis, L. SCL-90-R: Symptom Checklist 90-Revised: Administration, Scoring, and Procedures Manual. Clinical Psychometrics Research; Towson, MD: 1994.

31. DeVito Dabbs AJ, Hoffman L, Dauber J, Zullo T, Iacono A. Evaluating the reliability and validity of the Questionnaire for Lung Transplant Patients. Prog Transplant. 2002; 12(3):191-200. [PubMed: 12371045]

32. DeVito Dabbs AJ, Kim Y, Vensak J, Studer S, Iacono A. Validation and refinement of the questionnaire for lung transplant patients. Prog Transplant. 2004; 14(4):338-345. [PubMed: 15663019] 
33. DeVito Dabbs, Al; Johnson, B.; Wardzinski, WT.; Iacono, A.; Studer, S. Development and evaluation of the electronic version of the Questionnaire for Lung Transplant Patients (e-QLTP). Prog Transplant. 2007; 17(1):29-35. [PubMed: 17484242]

34. Hsieh H, Shannon SE. Three approaches to qualitative content analysis. Qual Health Res. 2005; 15(9):1277-1288. [PubMed: 16204405]

35. DeVito Dabbs AJ, Hoffman LA, Swigart V, et al. Striving for normalcy: symptoms and the threat of rejection after lung transplantation. Soc Sci Med. 2004; 59(7):1473-1484. [PubMed: 15246175]

36. Lefaiver CA, Keough VA, Letizia M, Lanuza DM. Quality of life in caregivers providing care for lung transplant candidates. Prog Transplant. 2009; 19(2):142-152. [PubMed: 19588664]

37. Ullrich G, Jansch H, Schmidt S, Struber M, Niedermeyer J. The experience of the support person involved in a lung transplant programme: results of a pilot study. Eur J Med Res. 2004; 9(12):555652. [PubMed: 15689302]

38. Kurz JM. Experiences of well spouses after lung transplantation. J Adv Nurs. 2001; 34(4):493500. [PubMed: 11380716] 


\section{Notice to CE emollees}

A closed-book, multiple-choice examination following this article tests your ability to accomplish the following objectives:

1. Describe the impact of stress on caregivers of transplant recipients

2. Compare the emotional and mental health reports of lung transplant recipients and their caregivers

3. Discuss imphcations for transplant professionals in assessing caregiver burden 


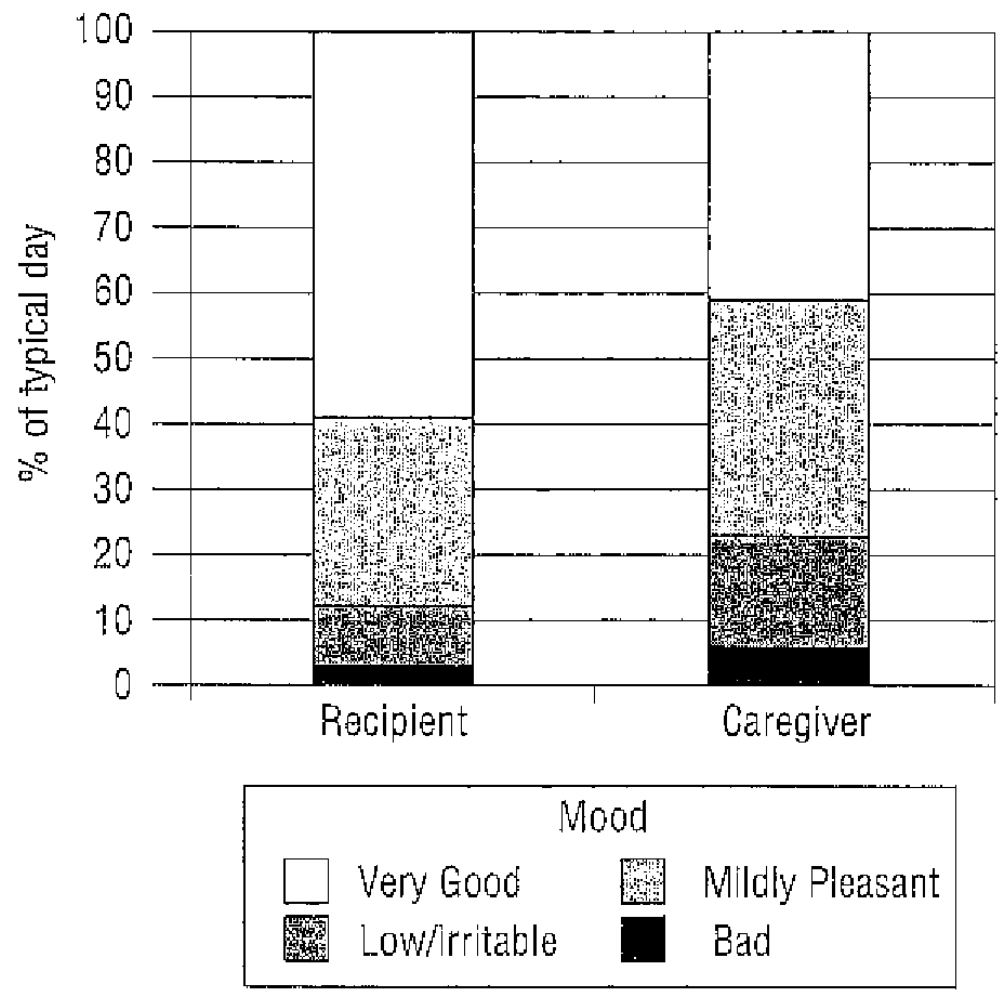

Figure 1.

Figure Comparison of daily mood ratings between recipients and caregivers. 


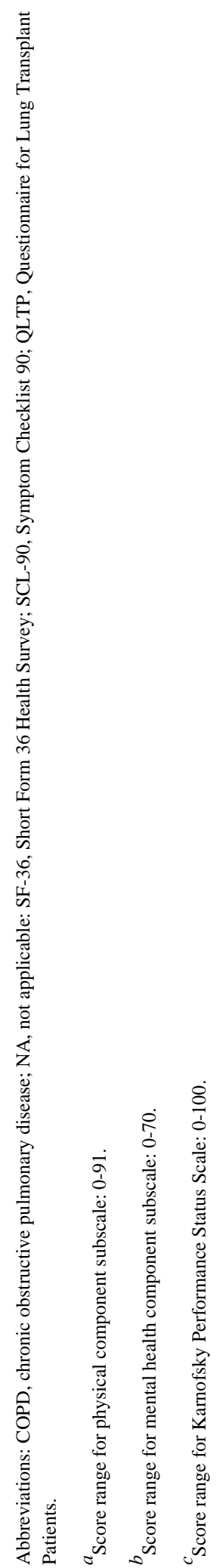


Table 2

Categorization of daily activities

\begin{tabular}{|c|c|}
\hline Categories $^{a}$ & Example activities \\
\hline $\begin{array}{l}\text { Health-related activities: } \\
\qquad 88(30 \%)\end{array}$ & $\begin{array}{l}\text { Medication taking } \\
\text { - Organizing medications } \\
\text { - Taking medications } \\
\text { Health monitoring } \\
\text { - Taking vitals } \\
\text { - Monitoring blood glucose } \\
\text { Medical appointments } \\
\text { - Keeping appointments } \\
\text { - Preparing for appointments } \\
\text { Therapy } \\
\text { - Breathing treatments } \\
\text { - Exercises }\end{array}$ \\
\hline $\begin{array}{l}\text { Leisure activities: } \\
59(20 \%)\end{array}$ & $\begin{array}{l}\text { Knitting } \\
\text { Watching television }\end{array}$ \\
\hline $\begin{array}{l}\text { Household chores: } \\
57(19 \%)\end{array}$ & $\begin{array}{l}\text { Preparing meals } \\
\text { Cleaning }\end{array}$ \\
\hline $\begin{array}{l}\text { Care of dependents: } \\
19(6 \%)\end{array}$ & $\begin{array}{l}\text { Feeding pets } \\
\text { Taking children to their activities }\end{array}$ \\
\hline Errands: $29(11 \%)$ & $\begin{array}{l}\text { Banking } \\
\text { Mailing }\end{array}$ \\
\hline Grooming: $17(6 \%)$ & $\begin{array}{l}\text { Showering } \\
\text { Dressing }\end{array}$ \\
\hline $\begin{array}{l}\text { Job-related activities: } \\
\qquad 12(5 \%)\end{array}$ & $\begin{array}{l}\text { Meeting } \\
\text { Checking work e-mails }\end{array}$ \\
\hline Resting $b: 5(3 \%)$ & $\begin{array}{l}\text { Napping } \\
\text { Trying to fall asleep }\end{array}$ \\
\hline
\end{tabular}


Table 3

Categorization of emotions associated with daily activities

\section{Categories $^{a}$}

\begin{tabular}{|c|c|}
\hline $\begin{array}{l}\text { Examples of negative } \\
\text { emotions, } 61(44 \%) \\
\end{array}$ & $\begin{array}{l}\text { Examples of positive } \\
\text { emotions, } 77(56 \%)\end{array}$ \\
\hline $\begin{array}{l}\text { - Annoyed } \\
\text { - Angry } \\
\text { - Uncomfortable } \\
\text { - Dread } \\
\text { - Pressured } \\
\text { - Rushed } \\
\text { - Bored } \\
\text { - Scared } \\
\text { - Depressed } \\
\text { - Hopeless } \\
\text { - Pissed off }\end{array}$ & $\begin{array}{l}\text { - Blessed } \\
\text { - Thankful } \\
\text { - Optimistic } \\
\text { - Enthusiastic } \\
\text { - Free } \\
\text { - Motivated } \\
\text { - Productive } \\
\text { - Useful } \\
\text { - Fortunate } \\
\text { - Content } \\
\text { - Loved }\end{array}$ \\
\hline
\end{tabular}

${ }^{a}$ Items per category ( $\%$ of total items). 